\title{
Research on China's Ecological Welfare Performance Evaluation and Improvement Path from the Perspective of High- Quality Development
}

\author{
Rong Wang $(\mathbb{D})$ and Yue Feng \\ Nanjing Institute of Technology, Jiangning Science Park, No. 1 Hongjing Avenue, Nanjing, Jiangsu 211167, China \\ Correspondence should be addressed to Rong Wang; wxr920@163.com
}

Received 3 December 2019; Revised 2 February 2020; Accepted 3 February 2020; Published 22 February 2020

Academic Editor: Anna Vila

Copyright (c) 2020 Rong Wang and Yue Feng. This is an open access article distributed under the Creative Commons Attribution License, which permits unrestricted use, distribution, and reproduction in any medium, provided the original work is properly cited.

\begin{abstract}
Based on the data of China's ecological environment from 2006 to 2018, the paper uses the super-efficiency DEA and Malmquist index methods to evaluate China's ecological welfare performance from a static and dynamic perspective. Based on this, the Theil index is used to analyze the group's ecological welfare performance. The internal and intergroup differences show that, from the static evaluation results, China's ecological welfare performance is in a situation of "high in the east, low in the west, and average in the central region." There is not much difference between the eastern and central regions, while the ecological welfare performance in the western region is low. From the results of dynamic evaluation, the overall level of regional ecological welfare performance in China has improved in recent years, and the average Malmquist index has exceeded 1, indicating that the growth pattern of ecological welfare performance has shifted to high quality, but the degree of increase in each region is different. There is still much room for improvement in ecological welfare performance; from the perspective of intragroup and intergroup differences, the intragroup differences and intergroup differences in the three major regions have generally maintained a continuous downward trend, and the contribution of the differences in ecowelfare performance between group rate has a clear advantage. Finally, corresponding suggestions are put forward based on the empirical results of the paper.
\end{abstract}

\section{Introduction}

China’s long-term preference for economic growth has led to an imbalance in resource allocation and development, which has constrained the orderly improvement of overall welfare levels and brought serious ecological and environmental problems. How to reduce the negative impact of economic growth on the environment and ecology while improving the subjective perception level of residents' quality of life and happiness will be a major issue that policymakers must pay attention to in the future. In short, balancing the relationship between the ecological environment, social welfare, and economic growth can better achieve balanced and sustainable development. In 2017, China's economic growth has moved from high-speed growth to a stage of high-quality growth. Economic growth has shifted from a high dependence on energy, real estate, and cheap labor to a more dependent growth mode such as new industries, new products, and new technologies. Quality development is not the goal pursued by economic development, but a tool to achieve sustainable economic and social development. It originates from the people and eventually returns to the people. The country's economic development and improvement of the ecological environment rests on the people, and everything needs to benefit from the people starting from this. One of the goals of highquality economic development is to improve the level of ecological welfare performance and increase people's satisfaction with life. Ecological welfare performance refers to the efficiency of converting natural consumption into welfare levels. At a certain level of natural consumption or welfare, ecological welfare performance reflects the degree of sustainable development of a country or region, or whether the country or region is continuously approaching or 
developing away from sustainable development, new research perspectives, and analytical tools for sustainable development. Daly [1] first proposed to evaluate the sustainable development status of countries by calculating the improvement in the level of welfare brought by the unit natural consumption and expressed it as services (utility or welfare that humans ultimately obtain from ecosystems) and throughput. The ratio of the amount of energy (the sum of the low entropy energy and materials that humans obtain from the ecosystem and the high entropy waste that is eventually discharged to the ecosystem) is the ecological welfare performance [2]. Since then, as the research on ecological welfare performance has continued, the measurement methods have also expanded from a single indicator to the ratio method and the input-output method. The selection of "welfare" indicators has always been the key to measurement. Because subjective welfare indicators are relatively random, scholars tend to choose objective welfare for characterization. Objective welfare has experienced the evolution from GDP to GNP/ISEW/CPI/HDI. Currently, the most widely used indicator is the Human Development Index (HDI) issued by the United Nations Development Programme UNDP in the Human Development Report. The three dimensions of economy, education, and health are collectively embodied, with authority and vertical and horizontal comparability.

In the context of sustainable development, how to better avoid the emergence of natural consumption into low-welfare levels requires effective monitoring and comprehensive evaluation of the specific development of each region, so it is necessary to establish ecological welfare performance as the core The evaluation system of indicators can more accurately and scientifically evaluate the ecological welfare performance level at the regional level in China, which has a strong theoretical value and practical guiding significance for eventually improving the level of ecological civilization in China's cities.

\section{Literature Review}

The performance of ecological welfare reflects the efficiency of input into welfare level, that is, the efficiency of ecological input and resource input into the human welfare level. This indicator reflects the degree of regional sustainable development and also shows that the level of ecological welfare performance can be analyzed. Sustainable development provides analytical tools and research perspectives. Ecowelfare performance was first proposed by the economist Daly $[1,3]$, who argued that when assessing the degree of sustainable development in a country, it is necessary to measure the relation between the consumption of ecological resources and the level of welfare that humans receive and express this relationship as "Service/Throughput," where Service is the level of welfare that humans receive under the consumption of ecological resources and Throughput is the total amount of ecological resources consumed by unit welfare or waste discharge. Later, Daly proposed that the development of human society has entered from the "empty world" to the "full world." The former refers to the relatively abundant state of resources, and the latter means that the ecological environment has become scarce. It is an important way to measure the level of social welfare. Since then, Common [4] has constructed an empirical model to measure the country's ecological welfare performance; in order to evaluate the country's economic growth mode, the main idea is to use the ratio between the welfare level and environmental input to measure the level of ecological performance. Foreign scholars Dietz et al. [5] evaluated ecowelfare performance from another perspective, using the ratio of life expectancy at birth to per capita ecological footprint. Using panel data analysis, the ecological welfare performance and per capita GDP were U-shaped curve.

In recent years, along with the deterioration of the global ecological environment, how to improve the people's living welfare while improving the environmental quality has become the focus of academic, government, and people. In particular, the performance of ecological welfare has become a hot topic for scholars. Domestic scholars have accumulated research in this field. The rich research results provide a reference for the research of this topic. Domestic scholar Liu [6] pointed out that the high-speed development stage considers environmental remediation and protection expenditure as a cost factor, while the high-quality growth stage regards the environment as the goal pursued by development and is an important part of social welfare. Fan [7] proposed that the ecological space should be planned from a long-term perspective, and the environmental and ecological policies should be ensured to ensure the safety of the ecological environment, improve the performance of ecological welfare, and improve the quality of economic growth. Long et al. [8] constructed the ecological welfare performance evaluation index system by the DEA method and measured the ecological performance level of 35 cities. The ecological welfare performance of coastal cities is obviously higher than that of the developed areas such as the Yangtze River Delta. The performance level of ecological welfare in the east is higher than that in the central and western regions. On this basis, the main factors affecting the performance of ecological welfare are also analyzed. Feng and Yuan [9] used the human development index and per capita ecological footprint to analyze the ecological welfare performance levels of 30 provinces and cities in China and analyzed the factors affecting the regional ecological welfare performance level based on the LMDI decomposition method. The main factors are decomposed into technical effects and service effects, and the service effects and ecological welfare performance are negatively correlated, while the technical effects are positively correlated. Song and Jin [10] analyzed the relationship between resource mismatch and environmental welfare performance. The study found that resource mismatch has a negative impact on regional environmental welfare performance through spatial spillover effects, while resource mismatching regional microenvironment Welfare performance has a significant negative impact and has no significant impact on macroenvironmental performance. Xiao and Zhang [11] used the improved SFA model to measure the ecological welfare performance of 30 provinces and cities in China. The study found that the regional 
differences are large, and Beijing-Zhejiang-GuangdongShaanxi has been formed as a pivot point and radiated to the area along the line. Liu [12] used the LMDI factor decomposition model to evaluate the impact of technical and service effects on the performance of energy welfare effects. The study found that China's energy performance and welfare technology effects are higher and negative effects are lower, but the total effect is negative, indicating that China's overall welfare performance is low.

In summary, domestic and foreign scholars have made rich achievements in the field of ecological welfare performance, which has important reference and reference for the research of this topic, but still has some room for expansion: first, most of the existing research has considered objective welfare or subjective welfare, such as the Human Development Index and the Happy Planet Index, respectively, but lack literature that comprehensively considers subjective and objective welfare. Second, the existing research considers more static and lacks the literature for dynamic comparison. Third, research on the improvement of ecological welfare performance in the high-quality development stage has not found relevant research and has a large expansion space from a new perspective. In view of this, the evaluation of the ecological welfare performance and the improvement path in the high-quality development stage can more accurately and scientifically evaluate the level of ecological welfare performance at the national level, which has strong theoretical value and reality guiding significance for improving the performance level of China's ecological welfare.

The main contributions of this paper are as follows. First, in the perspective of high-quality development of China's economy, the improvement of ecological welfare performance is an important driving force for achieving highquality development. Therefore, evaluating China's ecological welfare performance has important practical guiding significance. Second, in empirical analysis, taking full account of the static changes and dynamic changes of China's ecological welfare performance, it provides a theoretical reference for exploring the improvement of China's ecological welfare performance. Third, it analyzes the performance of ecological welfare in different regions of China and the reasons for differences in detail. Regionalization policies provide a policy basis.

\section{Method}

3.1. The Super-Efficiency DEA Method. This paper selects the super-efficiency DEA method to measure the regional ecoefficiency in Jiangsu Province. This method uses convex analysis and linear programming as tools, based on relative efficiency, and evaluates the relative effectiveness of the same type of decision-making unit (DMU) with multi-input and multi-indicator outputs. The DEA method does not require dimensionless data processing. At the same time, it does not require any weighting assumptions before building the DEA model. Instead, the actual data input and output decision unit needs to obtain the optimal weight, which can effectively solve the weighted area problem.

In order to compare regional ecoefficiency in Jiangsu Province, this project divided China into three regions, namely, the south, middle, and north regions, and compared the ecoefficiency of the three regions, with $\mathrm{N}$ as the decisionmaking unit. During the same period, each region in Jiangsu is a DMU (decision-making unit) and each decision-making unit (area) has $m$ inputs (input) and $n$ outputs (output), which represent resources, consumption, and output effectiveness. The $i$ unit is denoted as $\operatorname{DMU}_{i}(i=1,2, \ldots, N)$, and its input and output forms are

$$
\begin{aligned}
& X_{i}=\left(x_{1 i}, x_{2 i}, \ldots, x_{m i}\right)^{T}>0, \\
& Y_{i}=\left(y_{1 i}, y_{2 i}, \ldots, y_{m i}\right)^{T}>0 .
\end{aligned}
$$

The corresponding weight vector is set to

$$
\begin{aligned}
& U=\left(\mu_{1}, \mu_{2}, \ldots, \mu_{m}\right)^{T} \geq 0, \\
& V=\left(\nu_{1}, v_{2}, \ldots, v_{n}\right)^{T} \geq 0 .
\end{aligned}
$$

The DMUi efficiency evaluation index is

$$
h_{i}=\frac{V^{T} Y_{i}}{U^{T} X_{i}}=\frac{\sum v_{r} y_{r i}}{\sum \mu_{j} x_{j i}}, \quad i=1,2,3, \ldots, N .
$$

Assume that the decision unit being evaluated is $i 0$, and $\mathrm{DMU}_{i 0}$ is recorded. Under the condition that the efficiency index of each decision unit does not exceed one, select the appropriate weight vector $U$ and $V$ to achieve $V^{T} Y_{i 0} / U^{T} X_{i 0}$. The maximum, that is, the optimization model of $\mathrm{DMU}_{i 0}$ is

$$
\left\{\begin{array}{l}
D\left(X_{i 0}, Y_{i 0}\right)=\max \left(\frac{V^{T} Y_{i 0}}{U^{T} X_{i 0}}\right), \\
\text { s.t. } \quad \frac{V^{T} Y_{i}}{U^{T} X_{i}} \leq 1, \\
U \geq 0, V \geq 0, \quad i=1,2,3, \ldots, N .
\end{array}\right.
$$

For the traditional DEA model, if multiple decision units are at the same time leading to the production frontier and multiple decision units are simultaneously effective, the model will not be able to further evaluate and compare the merits of effective decision units. Anderson and Peterson established an investment-oriented super-efficiency DEA model which is used to make up for this deficiency, which can make the effective decision unit efficiency value greater than one. The super-efficient DEA (SE-DEA) model is as follows:

$$
\left\{\begin{array}{l}
D\left(X_{i 0}, Y_{i 0}\right)=\max \left(\frac{V^{T} Y_{i 0}}{U^{T} X_{i 0}}\right), \\
\text { s.t. } \quad \frac{V^{T} Y_{i}}{U^{T} X_{i}} \leq 1, \\
U \geq 0, V \geq 0, \quad(i=1,2,3, \ldots, N), i \neq i_{0} .
\end{array}\right.
$$


The advantages of this method are as follows. First, this method has objectivity, avoiding subjective consciousness; second, DEA method does not need to be normalized; third, it can reflect the effectiveness of production activities; fourth, it can provide auxiliary management information for producers.

3.2. Malmquist Index. Whether it is the super-efficient SBM model or the traditional DEA model, the analysis of both is based on the static perspective, so it is difficult to accurately analyze the dynamic efficiency changes of the decisionmaking units in the interperiod, and it is also impossible to deeply identify the causes of efficiency fluctuations [13]. Therefore, according to the research results of Stem Malmquist, Fare et al. introduced the DEA model to propose the Malmquist index that can be used to evaluate the dynamic change of efficiency. This index can help us to more comprehensively and deeply grasp the regional ecological welfare performance changes and the motivations and various types of changes. Change the specific contribution level [14]; on this basis, put forward more realistic decisionmaking suggestions to promote the construction of regional ecological civilization and sustainable development in China. In the following article, the paper will detail the Malmquist index construction process.

Fare et al. [14] constructed the Malmquist Productivity Index TPF from $t$ to $t+1$ to analyze the movement of consumption constraints on different difference curves:

$$
\begin{aligned}
\mathrm{TPE}= & M\left(x^{t+1}, y^{t+1}, x^{t}, y^{t}\right)=\frac{D^{t+1}\left(x^{t+1}, y^{t+1}\right)}{D^{t}\left(x^{t}, y^{t}\right)} \\
& \times \sqrt{\frac{D^{t}\left(x^{t+1}, y^{t+1}\right) \times D^{t}\left(x^{t}, y^{t}\right)}{D^{t+1}\left(x^{t+1}, y^{t+1}\right) \times D^{t+1}\left(x^{t}, y^{t}\right)}},
\end{aligned}
$$

where $D^{t}\left(x^{t}, y^{t}\right)$ and $D^{t}\left(x^{t+1}, y^{t+1}\right)$ are the distance functions of the decision unit with the $t$ period data as the reference set, the $t$ period and the $t+l$ period, respectively, $D^{t+1}\left(x^{t}, y^{t}\right)$ and $D^{t+1}\left(x^{t+1}, y^{t+1}\right)$ The distance function of the decision unit of $t$ period and $t+1$ period is the data of $t+1$ period as the reference set, respectively.

So, the Malmquist index is broken down into the Technology Change Index EC and the Technology Progress Index TC:

$$
\begin{aligned}
& \mathrm{EC}=\frac{D^{t+1}\left(x^{t+1}, y^{t+1}\right)}{D^{t}\left(x^{t}, y^{t}\right)} \\
& \mathrm{TC}=\sqrt{\frac{D^{t}\left(x^{t+1}, y^{t+1}\right) \times D^{t}\left(x^{t}, y^{t}\right)}{D^{t+1}\left(x^{t+1}, y^{t+1}\right) \times D^{t+1}\left(x^{t}, y^{t}\right)}} .
\end{aligned}
$$

That is, $\mathrm{TPF}=\mathrm{EC} \times \mathrm{TC}$ and $\mathrm{EC}=\mathrm{PTE} \times \mathrm{SE}$, where

$$
\begin{aligned}
\mathrm{PTE} & =\frac{D^{t+1}\left(x^{t+1}, y^{t+1} \mid \mathrm{VRS}\right)}{D^{t}\left(x^{t}, y^{t} \mid \mathrm{VRS}\right)}, \\
\mathrm{SE} & =\frac{D^{t+1}\left(x^{t+1}, y^{t+1} \mid \mathrm{CRS}\right)}{D^{t+1}\left(x^{t+1}, y^{t} \mid \mathrm{VRS}\right)} \times \frac{D^{t}\left(x^{t}, y^{t} \mid \mathrm{VRS}\right)}{D^{t}\left(x^{t}, y^{t} \mid \mathrm{CRS}\right)} .
\end{aligned}
$$

VRS means that the scale return is variable, and CRS means that the scale return is constant.

Through the abovementioned analysis, the Malmquist index can be decomposed into the following form:

$$
M\left(x^{t+1}, y^{t+1}, x^{t}, y^{t}\right)=\mathrm{EC} \times \mathrm{TC}=\mathrm{PTE} \times \mathrm{SE} \times \mathrm{TC},
$$

where Malmquist-Productivity Change Index (TPF) represents the productivity change of a company from the $t$ period to the $t+1$ period, and its value is the value of the production technology of the enterprise from the $t$ period to the $t+1$ period. The geometric mean is multiplied by the technical efficiency variation value. If the value of $M$ is greater than 1 , it means that the productivity of the enterprise is generally increasing during the period; if the value of $M$ is less than 1 , it means that the productivity of the enterprise is generally declining during the period.

EC-Technology Change Index-represents the measure index of the catching degree of the production possibility boundary of each decision-making unit in the period from $t$ period to $t+1$ under the condition of constant scale compensation and free disposal of factors. It reflects the change of relative efficiency in this period, and its value is equal to the difference between the input and output of enterprises and the efficiency of enterprises in the period of $t+1$ divided by the difference between input and output of enterprises in the $t$ period, that is, the degree of imitation of efficiency changes. If the value of EC is greater than 1 , it indicates that the technical efficiency of the enterprise has an improvement trend during the period from $t$ to $t+1$; if the value of EC is less than 1 , it indicates that the technical efficiency of the enterprise decreases during the period from $t$ to $t+1$. In addition, the EC can be split into a scale efficiency change index (SE) and a pure technical efficiency change index (PTE).

TC-Technology Progress Index-represents the overall change of production technology in the period from $t$ to $t+1$, the value of which is equal to the change of production technology of enterprises in $t+1$ period and the production technology of enterprises in $t$ period. The geometric mean of the change values reflects the degree of innovation in the production technology of the enterprise during this period. If the value of TC is greater than 1, it indicates that the production technology of the enterprise as a whole is increasing during the $t-t+1$ period; if the value of TC is less than 1 , it indicates that the production technology of the enterprise has declined during the period.

SE-Scale Change Index-represents the proximity of the DMU to the optimal scale based on the long-term perspective. If the value is greater than 1 , it reflects the tendency of the DMU to be optimally approached in the long-term perspective. It shows that the DMU gradually deviates from the optimal scale in the long-term perspective.

Calculating the distance function in different periods can be directly calculated by using the DEA model. However, if the DEA model is used based on the variable assumption of scale returns, there may be no solution. In this case, the super-SBM model needs to be introduced. 
3.3. Theil Index. Theil index or Theil's entropy measure was proposed by Theil in 1967. This indicator is mainly used to evaluate income imbalances. In the initial stage, the Theil coefficient was mainly used to analyze the income gap. Later, its application scope was further expanded and it was used in the study of regional differences. From its advantages, it is mainly decomposable, which can refine the overall regional differences and then accurately judge the differences within and between groups. The Theil coefficient is to select the concepts of information volume and entropy as the starting point to explore inequality and difference.

Entropy in the Theil index is interpreted as the average amount of information in information theory. Specifically, assuming that the probability of occurrence of an event $E$ is $P$, then the occurrence of the event $E$ is proved under a certain message, and the amount of information contained in the message can be expressed as follows:

$$
h(p)=\ln \left(\frac{1}{p}\right)
$$

Suppose that a complete event group is composed of $n$ occurrences $\left(E_{1}, E_{2}, \ldots, E_{n}\right)$ in the order of their respective occurrence probabilities $\left(p_{1}, p_{2}, \ldots, p_{n}\right)$, then the Theil index formula is

$$
\sum_{i=1}^{n} p_{i}=1
$$

The entropy or expected information refers to the sum of the product of each event's information and the corresponding probability:

$$
H(x)=\sum_{i=1}^{n} p_{i} h\left(p_{i}\right)=\sum_{i=1}^{n} p_{i} \log \left(\frac{1}{p_{i}}\right)=-\sum_{i=1}^{n} p_{i} \log \left(p_{i}\right) .
$$

The concept of the entropy index in information theory, when analyzing the income gap, can interpret the measurement of the income gap as the amount of information involved in the message of converting the population share into the income share. The Theil index is only a special case in the application of the entropy index. Its expression formula is

$$
T=\frac{1}{n} \sum_{i=1}^{n} \frac{y_{i}}{\bar{y}} \log \left(\frac{y_{i}}{\bar{y}}\right),
$$

where $T$ is the Theil index and $y_{i}$ and $\bar{y}$ are the income of the $i$ individual and the average income of all individuals.

One of the salient features of the Theil index is its decomposability. Suppose a sample containing $n$ individuals is divided into $K$ groups. Each group is $g_{k}(k=1,2, \ldots, K)$, and the number of individuals in the $k$ th group $g_{k}$ is $n_{k}$, then $\sum_{k=1}^{K} n_{k}=n, y_{i}$ and $y_{k}$ represent the income share of a certain body $i$ and the total income share of a group $K$, respectively. Let $T_{b}$ and $T_{w}$ be groups between intragroup gaps and within intragroup gaps, and the Theil index can be broken down as follows:

$$
T=T_{b}+T_{w}=\sum_{k=1}^{K} y_{k} \log \frac{y_{k}}{n_{k} / n}+\sum_{k=1}^{K} y_{k}\left(\sum_{i \in g_{k}} \frac{y_{i}}{y_{k}} \log \frac{y_{i} / y_{k}}{1 / n_{k}}\right) .
$$

In the abovementioned formula, the gap $T_{b}$ distance between groups and the gap $T_{w}$ within groups have the following expressions:

$$
\begin{aligned}
& T_{b}=\sum_{k=1}^{K} y_{k} \log \frac{y_{k}}{n_{k} / n}, \\
& T_{w}=\sum_{k=1}^{K} y_{k}\left(\sum_{i \in g_{k}} \frac{y_{i}}{y_{k}} \log \frac{y_{i} / y_{k}}{1 / n_{k}}\right) .
\end{aligned}
$$

Not only that, the intragroup gap is actually the sum of the intragroup gaps in each group, so its calculation formula is the same as this overall calculation formula, and it differs only in the sample size.

\section{Results and Discussion}

\subsection{Static Evaluation of China's Regional Ecological Welfare Performance}

4.1.1. Construction of Indicator System. In this study, the output choice is the level of social welfare; the input choice is ecological consumption; the social welfare level is the human development index provided by the United Nations Development Programme, which mainly includes three dimensions of economy, health, and education [15-17]; Ecological consumption is mainly concentrated on environmental pollution and resource consumption. In addition, the model construction strictly follows the principles of science, operability, and systemicity. The resource consumption indicators are mainly selected for land resource consumption, water resource consumption, and energy consumption. The specific index construction system is shown in Table 1.

\subsubsection{Data Source and Processing}

(1) Social welfare level: all economic activities are based on improving people's subjective well-being. The core participants in economic activities are individuals. The overall national strength of the country depends largely on the individual's development space, and quality of life. This study uses the Human Development Index (HID) to measure the level of social welfare (WB), which is an indicator established by the United Nations Development Programme in 1990. It is mainly used to measure the level of socioeconomic development of member states. The 
TABLE 1: Index system construction.

\begin{tabular}{|c|c|c|c|}
\hline Category & Level one indicator & Level two indicator & Level three indicator \\
\hline \multirow{6}{*}{$\begin{array}{l}\text { Input } \\
\text { indicators }\end{array}$} & \multirow{3}{*}{$\begin{array}{l}\text { Ecological resource } \\
\text { consumption }\end{array}$} & \multirow{3}{*}{$\begin{array}{l}\text { Water consumption } \\
\text { Land resource } \\
\text { consumption } \\
\text { Energy consumption }\end{array}$} & Per capita water consumption \\
\hline & & & Per capita construction land area \\
\hline & & & Per capita coal consumption and per capita electricity consumption \\
\hline & \multirow{3}{*}{ Environmental pollution } & Wastewater discharge & $\begin{array}{c}\text { Per capita chemical oxygen demand and per capita ammonia nitrogen } \\
\text { emissions }\end{array}$ \\
\hline & & Exhaust gas emissions & $\begin{array}{l}\text { Per capita sulfur dioxide emissions, per capita nitrogen oxide } \\
\text { emissions, and per capita smoke (powder) dust emissions }\end{array}$ \\
\hline & & Solid waste discharge & $\begin{array}{c}\text { Per capita general industry solid waste production and per capita } \\
\text { domestic waste removal volume }\end{array}$ \\
\hline \multirow{3}{*}{$\begin{array}{l}\text { Output } \\
\text { indicators }\end{array}$} & \multirow{3}{*}{ Welfare Level (HDI) } & Resident income level & Per capita GDP \\
\hline & & $\begin{array}{c}\text { Educational } \\
\text { development level }\end{array}$ & Per capita years of education \\
\hline & & $\begin{array}{l}\text { Healthy living } \\
\text { standard }\end{array}$ & Per capita of life expectancy \\
\hline
\end{tabular}

quality of life of residents in member countries has been widely used internationally. The current academic indicators on the level of social welfare are highly controversial. The three most common indicators are GDP and indicators derived from GDP such as GS, GPI, and ISEW; infant mortality and life expectancy at birth; and human development index. A comprehensive indicator represented. This index can comprehensively reflect the basic connotation of human development. It not only involves economic welfare but also covers nonemergency benefits, so it is widely used internationally. Although this indicator only covers the three dimensions of health, education, and income, it has strong practicability because of its good operation and high degree of refinement. To this end, this refers to the previous study of the selection of the Human Development Index to measure the country's social welfare level; according to the United Nations Development Programme's calculation of the Human Development Index, we need to measure education, health, and income levels; on this basis, normalize the relevant data, calculate the geometric mean of the abovementioned three-dimensional index, and assign a weight of $1 / 3$ to each dimension index to obtain the human development index HDI. The greater the deviation of the HDI value from 1 , the lower the regional development level and the lower the ecological input index. The HDI calculation formula is as follows:

$$
\mathrm{HDI}=\sqrt[3]{\mathrm{LEI} \times \mathrm{EI} \times \mathrm{II}} .
$$

In the abovementioned formula, EI, LEI, and II represent the education index, life expectancy index, and income index, respectively. The calculation of life expectancy refers to the following formulas, which are derived from the China Population and Employment Statistics Yearbook:

life expectancy index $(\mathrm{LEI})=\frac{\text { Average life expectancy }-20}{83.4-20}$,

where 20 is the minimum life expectancy and 83.4 is the highest life expectancy

The level of education is usually measured by the expected years of education and the average years of schooling for people over the age of 25 , but it is difficult to obtain data on the expected years of education in China, and the population of 25 years of age or older has not been specifically counted in China. The average number of years of schooling is therefore replaced by the average age of education for people aged 6 and over. The calculation formula is

$\int$ Average years of schooling $(\mathrm{PE})=\frac{6 \times P_{\text {Elementary school }}+9 \times P_{\text {junior high school }}+12 \times P_{\text {high school }}+16 \times P_{\text {college or above }}}{P_{P_{\text {Elementary school }}}+P_{\text {junior high school }}+P_{\text {high school }}+P_{\text {college or above }}}$,

Expected years of schooling $(\mathrm{YE})=\sum_{i=1}^{4} W_{i} \times$ Gross enrollment rate of academic education at all levels, 
where $P$ represents the population of education qualifications, $W$ represents weights, and 60\%, 30\%, 30\%, and $40 \%$ are for primary, junior, senior, and junior colleges, respectively.

Average education index $(\mathrm{PEI})=\frac{\mathrm{PE}-0}{13.1-0}$,

Expected education index $(\mathrm{YEI})=\frac{\mathrm{YE}-0}{18-0}$,

$$
\text { Education index }(\mathrm{EI})=\frac{\sqrt{\mathrm{PEI} \times \mathrm{YEI}-0}}{0.978-0} \text {. }
$$

The income level is the actual income after the price change is removed, and the natural logarithm is taken when standardizing the index:

Income index $(\mathrm{II})=\frac{\ln (\text { per capita GDP })-\ln (100)}{\ln (7500)-\ln (100)}$,

where 100 is the minimum per capita GDP and 7500 is the maximum per capita GDP.

(2) Level of ecological resource consumption: the essence of ecological welfare performance is to obtain the maximum welfare level output with the least conversion of natural ecological inputs, which is also consistent with the DEA method's requirements for input and output indicators. Ecological inputs include resource consumption and environmental pollution. Resources refer to the collective name of various material elements such as material resources, financial resources, and human resources in a country or a certain area. The paper divides into two categories of natural resources and social resources. According to the connotation of ecological efficiency, the resource consumption involved in this article refers only to natural resources. Based on the availability and typicality of the data, this article refers to the practice of $\mathrm{Du}$ et al. $[2,18]$ to select the energy consumption index, land resource consumption index, and water consumption index as the ecological resource consumption index system.

Environmental pollution indicators: in the process of improving the welfare of residents, cities must consume certain natural resources. At the same time, due to social and economic activities (especially in the case of low resource utilization), it is inevitable that a certain amount of pollution emissions are generated, mainly the discharge of regional solid waste, waste gas, and waste water. This is also the price to be paid for the output of human welfare and economic activities. In fact, it is also an input or cost, which is the "cost of environmental degradation." "Investment," taking into account the availability of data, this study proposed to use industrial pollution emissions data as an environmental pollution indicator instead. In addition, considering the limited number of samples, if the number of input-output indicators is too large, the DEA evaluation results will be distorted $[19,20]$. Therefore, the entropy method was introduced in this study to reduce the six environmental pollution emission subindicators. After the maintenance process, a general index is obtained, and the comprehensive index of pollutant weight and pollutant discharge is shown in Tables 2 and 3.

4.1.3. Source of Data. Taking into account the availability of data, this paper analyzes the data of 30 provinces (municipalities and autonomous regions) of Tibet, Hong Kong, Macao, and Taiwan from 2006 to 2018. All the raw data are from the China Statistical Yearbook of the relevant year, China Demographic Yearbook, China Education Statistics Yearbook, China Environmental Statistics Yearbook, China Science and Technology Statistical Yearbook, and China Energy Statistics Yearbook, as well as provincial statistical yearbooks and system statistics of the National Bureau of Statistics website. Missing data is obtained by interpolation and extrapolation.

4.1.4. Static Analysis Results of China's Regional Ecological Welfare Performance. The results of the calculation of regional ecological welfare performance of Chinese provinces according to the aforementioned research methods are shown in Table 4.

According to the abovementioned subregions, the overall ecological welfare performance is higher in Beijing, Shanghai, Jiangxi, and Hunan, both higher than 0.85, Beijing and Shanghai are the highest in China at 2.0, and Beijing and Shanghai are international metropolis. The aspect is that the government policy needs to pay more attention to the sustainable development of the environment and may be stricter in environmental regulation. On the contrary, Beijing and Shanghai have higher regional output value and have more income for environmental problems, so the performance value in ecological welfare is much higher than other regions. The ecological welfare performance reached 7 in the area below 0.5 , namely, Liaoning, Shanxi, Guizhou, Gansu, Qinghai, Ningxia, and Qinghai. The ecological welfare performance of these areas is low, and five of them are distributed in the west, indicating the ecological welfare of these areas. Performance is closely related to its level of economic development. The level of economic development determines the composition of its industrial structure. In economically underdeveloped areas, there are often more traditional extensive growth models, and the proportion of industries with high pollution, high emissions, and high energy consumption is high. At the same time, the government relaxed the tolerance for the environment for economic growth, thus causing the reality that the ecological welfare performance of these regions is low. The region between 0.5 and 0.9 accounts for the vast majority, accounting for 19 regions, and the ecological welfare performance of these regions is at a medium level. In addition, from the perspective of dynamic changes in data, the ecological welfare performance of most regions shows an increasing trend, indicating that with the development of the economy and the improvement of the quality of economic growth, all regions pay more and more attention to the regional ecological environment and continuously improve the regional ecological 
Table 2: Pollutant emission weights.

\begin{tabular}{lc}
\hline Pollutant emission index & Weights \\
\hline Per capita chemical oxygen demand emissions & 0.183 \\
Per capita ammonia nitrogen emissions & 0.191 \\
Per capita sulfur dioxide emissions & 0.162 \\
Per capita nitrogen oxide emissions & 0.153 \\
Per capita smoke (powder) dust emissions & 0.166 \\
Per capita general industry solid waste production & 0.088 \\
Per capita regional domestic garbage removal volume & 0.057
\end{tabular}

welfare performance. Thereby achieving coordinated development of economy, resources, and environment.

\subsection{Dynamic Measurement of Ecological Welfare Performance in Three Regions of China}

4.2.1. Measurement Results of Ecological Welfare Performance in Three Regions of China. This paper uses data from 30 to 20 years except the Tibet Autonomous Region and Hong Kong, Macao, and Taiwan regions and divides the province into three regions: the eastern region mainly includes Beijing, Tianjin, Hebei, Liaoning, Shanghai, Jiangsu, Zhejiang, Fujian, Shandong, Guangdong, Hainan, and other provinces; the central region mainly includes Shanxi, Jilin, Heilongjiang, Anhui, Jiangxi, Henan, Hubei, Hunan, and other provinces; the western region mainly includes Inner Mongolia, Guangxi, Chongqing, Sichuan, Guizhou, Yunnan, Shaanxi, Gansu, Qinghai, Ningxia, Xinjiang, and other provinces. The ecological welfare performance values of the three regions are obtained by the arithmetic mean method. The results are shown in Table 5.

Table 5 shows the regional total ecological welfare performance. It can be seen that the overall performance level of ecological welfare in the eastern region is higher, the value of the statistical year is above 1, the performance of central ecological welfare is lower than that in the east, but greater than the western region, and the performance of ecological welfare appears higher in eastern and lower in central and western. In order to analyze the trend and relationship between the three regions' ecological welfare performance, the abovementioned model is used to calculate the regional ecological welfare performance value and draw a line chart, as shown in Figure 1.

It can be seen from Figure 1 that, from the perspective of ecological welfare performance in the eastern, central, and western economic regions of China, there are significant differences in the performance of ecological welfare in the eastern, central, and western regions. The eastern ecological welfare performance is the highest, and the average annual efficiency value is above 1.0. The volatility is relatively flat, and the performance of ecological welfare has risen steadily, mainly related to the degree of economic development in the east. This indicates that in the recent years, the eastern region has paid more attention to the improvement of regional ecological welfare performance while developing the economy, which is in line with the country's sustainable development. The goal is to match. The performance of ecological welfare in the central and western regions is significantly lower than that in the eastern region, but the change is significantly larger than that in the east. The gap with the eastern region is shrinking, reflecting that the central and western regions are still focusing on economic growth and paying attention to the performance of ecological welfare. It is lower than the east, but in recent years, it has gradually begun to pay attention to the improvement of ecological welfare performance, and the performance of ecological welfare is on the rise.

\subsubsection{Dynamic Analysis of Regional Ecological Welfare} Performance in China. This paper introduces the DEAMalmquist index analysis method to empirically analyze the ecological welfare performance of 30 provinces and cities in China from 2006 to 2018 and processes the abovementioned performance data through MaxDEA software to obtain its Malmquist index and technological progress change index and technical efficiency. The average value of the change indicators, the specific results are shown in Table 6.

Based on the macrolevel, the Malmquist index of the 30 major provinces and cities in China is larger than that of the first one. This shows that with the implementation of a series of energy conservation and emission reduction policies during the "Twelfth Five-Year Plan" period, the national ecological civilization construction has entered in the new stage; this has greatly promoted the efficiency of the transformation of welfare output in various regions of China. Based on the technical efficiency change index, this index exceeds 1 in all other years from 2012 to 2013, indicating that the resource allocation initiative has promoted the improvement of ecological welfare performance in various regions; based on the technological progress change index, this index is excluded from 2011. By 2012, the number other than 1 in 2012 indicates that the technical level is continuously improving, which also provides an important support for further improving the performance of regional ecological welfare in China.

As far as the Chinese region is concerned, there are five regions in the 30 regions where the Malmquist index does not exceed one, namely, Hebei, Fujian, Anhui, Sichuan, and Anhui, and the rest are above 1, which means that most of China's regions are during the "Twelfth Five-Year Plan" period, corresponding measures have been taken to improve the level of ecological welfare performance. It is not difficult to find out that this index can continue to be analyzed. In terms of the technical efficiency change index, there are nine areas where the technical efficiency change index does not exceed one. In Ningxia, Shanxi, Sichuan, Chongqing, Hainan, Fujian, Zhejiang, Shanghai, and Hebei, nearly 30\% of the region still has a large space for resource allocation. The ecological carrying capacity of the five eastern regions is still relatively strong, indicating resources, and there is still room for improvement in the overall efficiency of the environment. In the future, it is necessary to continue to improve the resource utilization rate and total control level. From the analysis of the technological progress change index, there are six averages of the technological progress change index not exceeding 1, namely, Ningxia, Chongqing, 
TABLe 3: Comprehensive index of China's pollutant emissions from 2006-2018.

\begin{tabular}{|c|c|c|c|c|c|c|c|c|c|c|c|c|c|}
\hline Years & 2006 & 2007 & 2008 & 2009 & 2010 & 2011 & 2012 & 2013 & 2014 & 2015 & 2016 & 2017 & 2018 \\
\hline Pollutant discharge index & 0.103 & 0.093 & 0.091 & 0.095 & 0.085 & 0.084 & 0.079 & 0.073 & 0.069 & 0.065 & 0.062 & 0.053 & 0.048 \\
\hline
\end{tabular}

TABLE 4: Results of regional ecological welfare performance calculations in various provinces.

\begin{tabular}{|c|c|c|c|c|c|c|c|c|c|c|c|c|c|c|c|}
\hline Region & Province or city & 2006 & 2007 & 2008 & 2009 & 2010 & 2011 & 2012 & 2013 & 2014 & 2015 & 2016 & 2017 & 2018 & Mean \\
\hline \multirow{11}{*}{ Eastern } & Beijing & 2.665 & 2.681 & 2.765 & 2.774 & 2.798 & 2.835 & 2.887 & 2.925 & 3.036 & 3.119 & 3.161 & 3.143 & 3.167 & 2.920 \\
\hline & Tianjin & 0.612 & 0.616 & 0.628 & 0.635 & 0.649 & 0.729 & 0.768 & 0.782 & 0.798 & 0.854 & 0.886 & 0.891 & 1.012 & 0.758 \\
\hline & Hebei & 0.371 & 0.376 & 0.382 & 0.396 & 0.399 & 0.459 & 0.479 & 0.481 & 0.575 & 0.614 & 0.646 & 0.659 & 0.679 & 0.501 \\
\hline & Liaoning & 0.221 & 0.226 & 0.231 & 0.258 & 0.265 & 0.294 & 0.312 & 0.343 & 0.415 & 0.503 & 0.606 & 0.679 & 0.781 & 0.394 \\
\hline & Shanghai & 2.123 & 2.149 & 2.268 & 2.279 & 2.298 & 2.311 & 2.459 & 2.513 & 2.527 & 2.628 & 2.662 & 2.723 & 2.817 & 2.443 \\
\hline & Jiangsu & 0.621 & 0.229 & 0.636 & 0.641 & 0.759 & 0.779 & 0.799 & 0.801 & 0.826 & 0.857 & 0.879 & 0.889 & 0.901 & 0.740 \\
\hline & Zhejiang & 0.611 & 0.618 & 0.633 & 0.653 & 0.675 & 0.721 & 0.779 & 0.891 & 0.911 & 0.922 & 0.932 & 0.944 & 0.959 & 0.788 \\
\hline & Fujian & 0.509 & 0.522 & 0.529 & 0.546 & 0.565 & 0.572 & 0.635 & 0.737 & 0.799 & 0.817 & 0.892 & 0.899 & 0.919 & 0.688 \\
\hline & Shandong & 0.413 & 0.417 & 0.423 & 0.433 & 0.439 & 0.457 & 0.474 & 0.502 & 0.643 & 0.734 & 0.808 & 0.921 & 0.535 & 0.554 \\
\hline & Guangdong & 0.813 & 0.818 & 0.823 & 0.837 & 0.858 & 0.864 & 0.869 & 0.872 & 0.892 & 0.899 & 0.903 & 0.911 & 0.967 & 0.871 \\
\hline & Hainan & 0.734 & 0.736 & 0.742 & 0.749 & 0.759 & 0.785 & 0.809 & 0.811 & 0.817 & 0.823 & 0.863 & 0.886 & 0.879 & 0.799 \\
\hline \multirow{8}{*}{ Central } & & 343 & 0.346 & 0.351 & 0.358 & 0.369 & 0.38 & 0.393 & 0.403 & 411 & 0.424 & 0.439 & 0.455 & .468 & 0.395 \\
\hline & Jilin & 0.582 & 0.586 & 0.591 & 0.597 & 0.611 & 0.619 & 0.633 & 0.681 & 0.712 & 0.814 & 0.921 & 0.933 & .947 & 0.710 \\
\hline & Heilongjiang & 0.523 & 0.529 & 0.534 & 0.543 & 0.556 & 0.579 & 0.585 & 0.599 & 0.622 & 0.729 & 0.812 & 0.869 & 0.989 & 0.651 \\
\hline & Anhui & 0.651 & 0.655 & 0.669 & 0.672 & 0.682 & 0.699 & 0.775 & 0.836 & 0.853 & 0.867 & 0.879 & 0.882 & 0.891 & 0.770 \\
\hline & Jiangxi & 0.741 & 0.748 & 0.756 & 0.773 & 0.787 & 0.812 & 0.839 & 0.867 & 0.888 & 0.912 & 0.956 & 0.979 & 0.993 & 0.850 \\
\hline & Henan & 0.516 & 0.519 & 0.521 & 0.529 & 0.635 & 0.547 & 0.566 & 0.618 & 0.681 & 0.714 & 0.826 & 0.889 & 0.914 & 0.652 \\
\hline & Hubei & 0.513 & 0.519 & 0.528 & 0.541 & 0.556 & 0.569 & 0.575 & 0.599 & 0.601 & 0.669 & 0.702 & 0.752 & 0.846 & 0.613 \\
\hline & Hunan & 0.819 & 0.826 & 0.832 & 0.838 & 0.845 & 0.891 & 0.923 & 0.931 & 0.951 & 0.969 & 0.979 & 0.908 & 0.925 & 0.895 \\
\hline \multirow{11}{*}{ Western } & ner Mongo & 0.721 & 0.728 & 39 & 0.746 & 0.774 & 0.786 & 0.799 & 99 & 821 & 873 & 0.904 & 0.936 & 56 & 0.815 \\
\hline & Guangxi & 0.787 & 0.889 & 0.883 & 0.881 & 0.807 & 0.775 & 0.791 & 0.799 & 0.814 & 0.833 & 0.877 & 0.943 & .899 & 0.844 \\
\hline & Chongqing & 0.719 & 0.722 & 0.731 & 0.739 & 0.748 & 0.789 & 0.798 & 0.813 & 0.836 & 0.851 & 0.879 & 0.898 & 0.923 & 0.804 \\
\hline & Sichuan & 0.714 & 0.721 & 0.729 & 0.737 & 0.749 & 0.758 & 0.769 & 0.783 & 0.796 & 0.823 & 0.852 & 0.861 & 0.879 & 0.782 \\
\hline & Guizhou & 0.408 & 0.416 & 0.424 & 0.431 & 0.439 & 0.447 & 0.453 & 0.465 & 0.474 & 0.493 & 0.516 & 0.579 & 0.614 & 0.474 \\
\hline & Yunnan & 0.722 & 0.726 & 0.731 & 0.748 & 0.756 & 0.769 & 0.789 & 0.795 & 0.804 & 0.859 & 0.894 & 0.906 & 0.919 & 0.801 \\
\hline & Shaanxi & 0.723 & 0.729 & 0.737 & 0.744 & 0.759 & 0.779 & 0.789 & 0.811 & 0.844 & 0.871 & 0.887 & 0.896 & 0.907 & 0.806 \\
\hline & & 0.373 & 0.378 & 0.383 & 0.391 & 0.399 & 0.409 & 0.418 & 0.433 & 0.446 & 0.463 & 0.484 & 0.489 & 0.509 & 0.429 \\
\hline & Qinghai & 0.349 & 0.355 & 0.365 & 0.371 & 0.379 & 0.387 & 0.399 & 0.407 & 0.416 & 0.428 & 0.439 & 0.473 & 0.486 & 0.404 \\
\hline & Ningxia & 0.369 & 0.377 & 0.385 & 0.391 & 0.401 & 0.409 & 0.415 & 0.426 & 0.435 & 0.449 & 0.459 & 0.478 & 0.507 & 0.423 \\
\hline & Xinjiang & 0.358 & 0.366 & 0.379 & 0.385 & 0.394 & 0.402 & 0.416 & 0.428 & 0.431 & 0.444 & 0.459 & 0.498 & 0.561 & 0.425 \\
\hline \multicolumn{2}{|c|}{ National average } & 0.687 & 0.684 & 0.711 & 0.721 & 0.737 & 0.754 & 0.780 & 0.805 & 0.836 & 0.875 & 0.913 & 0.939 & 0.958 & 0.800 \\
\hline
\end{tabular}

TABLE 5: China's regional ecological welfare performance in 2006-2018.

\begin{tabular}{cccc}
\hline Year & Eastern & Central & Western \\
\hline 2006 & 0.881 & 0.586 & 0.568 \\
2007 & 0.853 & 0.591 & 0.582 \\
2008 & 0.914 & 0.598 & 0.590 \\
2009 & 0.927 & 0.606 & 0.596 \\
2010 & 0.951 & 0.630 & 0.600 \\
2011 & 0.982 & 0.637 & 0.610 \\
2012 & 1.025 & 0.661 & 0.621 \\
2013 & 1.060 & 0.692 & 0.634 \\
2014 & 1.113 & 0.715 & 0.647 \\
2015 & 1.161 & 0.762 & 0.671 \\
2016 & 1.203 & 0.814 & 0.695 \\
2017 & 1.231 & 0.833 & 0.723 \\
2018 & 1.238 & 0.872 & 0.742 \\
\hline
\end{tabular}

and relations. Anhui, Heilongjiang, Hebei, and the rest of the region are above 1 , indicating that most areas of technological progress are obvious, but in different regions, the degree of progress is different, among which Guangdong has the fastest progress. This is related to Guangdong's investment in human resources, material resources, and financial resources in technology development and innovation. At present, Shanghai, Beijing, and other first-line areas are also imitating Guangdong's practices.

\subsection{Theil Coefficient Analysis of Regional Ecological Efficiency Differences}

4.3.1. Theil Coefficient of Ecological Efficiency Differences in Three Regions of China. This article uses the Theil coefficient calculation formula to calculate the results, as shown in Table 7, and draws a line chart based on the data to reflect the changes in the Theil index of the regional ecoefficiency levels, as shown in Figure 2.

From Table 7 and Figure 2, it can be seen that the regional differences in the level of ecological welfare performance in the eastern region have continued to decrease year by year. From 2006 to 2018, the Theil coefficient has 


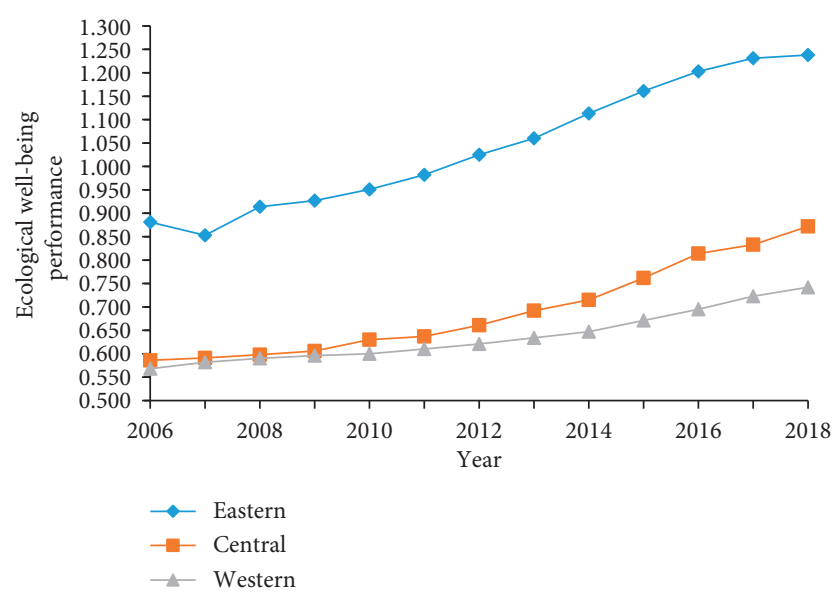

FIGURE 1: Trends in the performance values of ecological welfare in various regions of China.

TABLE 6: China regional ecological welfare performance Malmquist index.

\begin{tabular}{|c|c|c|c|}
\hline Region & $\begin{array}{l}\text { Technical } \\
\text { efficiency }\end{array}$ & $\begin{array}{c}\text { Technological } \\
\text { progress }\end{array}$ & $\mathrm{Mi}$ \\
\hline$\overline{\text { Beijing }}$ & 1.003 & 1.016 & 1.019 \\
\hline Tianjin & 1.001 & 1.024 & 1.026 \\
\hline Hebei & 0.926 & 0.982 & 0.971 \\
\hline Liaoning & 1.045 & 1.116 & 1.179 \\
\hline Shanghai & 0.923 & 1.165 & 1.113 \\
\hline Jiangsu & 1.001 & 1.192 & 1.121 \\
\hline Zhejiang & 0.991 & 1.013 & 1.027 \\
\hline Fujian & 0.911 & 1.002 & 0.987 \\
\hline Shandong & 1.042 & 1.016 & 1.117 \\
\hline Guangdong & 1.188 & 1.219 & 1.492 \\
\hline Hainan & 0.955 & 1.013 & 1.005 \\
\hline Shanxi & 1.055 & 1.156 & 1.223 \\
\hline Jilin & 1.001 & 1.002 & 1.005 \\
\hline Heilongjiang & 1.111 & 0.988 & 1.082 \\
\hline Anhui & 1.001 & 0.993 & 0.996 \\
\hline Jiangxi & 1.012 & 1.016 & 1.108 \\
\hline Henan & 1.061 & 1.033 & 1.112 \\
\hline Hubei & 1.134 & 1.116 & 1.298 \\
\hline Hunan & 1.011 & 1.009 & 1.015 \\
\hline $\begin{array}{l}\text { Inner } \\
\text { Mongolia }\end{array}$ & 1.228 & 1.097 & 1.442 \\
\hline Guangxi & 1.012 & 0.977 & 0.989 \\
\hline Chongqing & 0.981 & 0.999 & 1.002 \\
\hline Sichuan & 0.999 & 1.001 & 0.998 \\
\hline Guizhou & 1.035 & 1.087 & 1.161 \\
\hline Yunnan & 1.192 & 1.031 & 1.241 \\
\hline Shaanxi & 0.991 & 1.036 & 1.022 \\
\hline Gansu & 1.051 & 1.112 & 1.219 \\
\hline Qinghai & 1.033 & 1.112 & 1.149 \\
\hline Ningxia & 0.998 & 0.999 & 1.119 \\
\hline Xinjiang & 1.081 & 1.198 & 1.291 \\
\hline
\end{tabular}

gradually decreased from 0.1011 to 0.0666 , indicating that regional ecological welfare performance in recent years was affected by factors such as policies, technologies, and industrial structures, and the differences in ecological welfare performance in various regions in the east have been weakened to a certain extent; the differences in ecological welfare performance in the central region have fluctuated before 2010, and the ecological efficiency differences have decreased sharply after 2010, mainly due to the convergence of the economic structure of the central provinces; the Theil coefficient in the western region has remained relatively stable and has not changed significantly, maintaining the range of $0.1435-0.1792$.

In general, the Theil coefficient in the western region has maintained a high level among various regions. During the period of 2006-2018, the average value of the Theil coefficient reached 0.162 , which indicates that the ecological welfare performance in the western region is significantly different; the average values of Theil coefficients in the eastern and central regions are 0.096 and 0.105 , respectively. It can be clearly seen that the difference in ecological welfare performance in the eastern region is the smallest across the country.

\subsubsection{Theil Coefficient Analysis of Intragroup Differences and} Intergroup Differences in China's Regional Ecological Welfare Performance. According to the decomposability of the Theil index, the regional differences in China's ecological welfare performance can be divided into intergroup differences and intragroup differences. Table 8 and Figure 3 show the overall differences $(T)$ in China's ecological welfare performance and intragroup differences $\left(T_{w}\right)$ and intergroup differences $\left(T_{b}\right)$ from 2006 to 2018 .

It can be seen from Table 8 that between 2006 and 2018, except for 2010, the Theil coefficient is in a downward trend, from the initial 0.1148 to 0.1034 . This shows that, from a national perspective, regional differences in overall ecological welfare performance have generally maintained a steady downward trend.

It can be seen that the variation trend of the Theil coefficient within and between groups in China's regional ecological welfare performance is generally the same as the evolution trend of the National Theil coefficient, and the 
TABLe 7: Theil coefficients of ecological welfare performance in three regions of China.

\begin{tabular}{lccc}
\hline Year & Eastern & Central & Western \\
\hline 2006 & 0.1011 & 0.0998 & 0.1435 \\
2007 & 0.1045 & 0.1076 & 0.1446 \\
2008 & 0.1066 & 0.1161 & 0.1498 \\
2009 & 0.1087 & 0.1187 & 0.1587 \\
2010 & 0.1112 & 0.1234 & 0.1598 \\
2011 & 0.1033 & 0.1221 & 0.1624 \\
2012 & 0.1027 & 0.1176 & 0.1634 \\
2013 & 0.1013 & 0.1112 & 0.1698 \\
2014 & 0.0993 & 0.1032 & 0.1754 \\
2015 & 0.0966 & 0.0995 & 0.1711 \\
2016 & 0.0852 & 0.0894 & 0.1793 \\
2017 & 0.0745 & 0.0806 & 0.1694 \\
2018 & 0.0666 & 0.0799 & 0.1638 \\
Mean & 0.097 & 0.105 & 0.162 \\
\hline
\end{tabular}

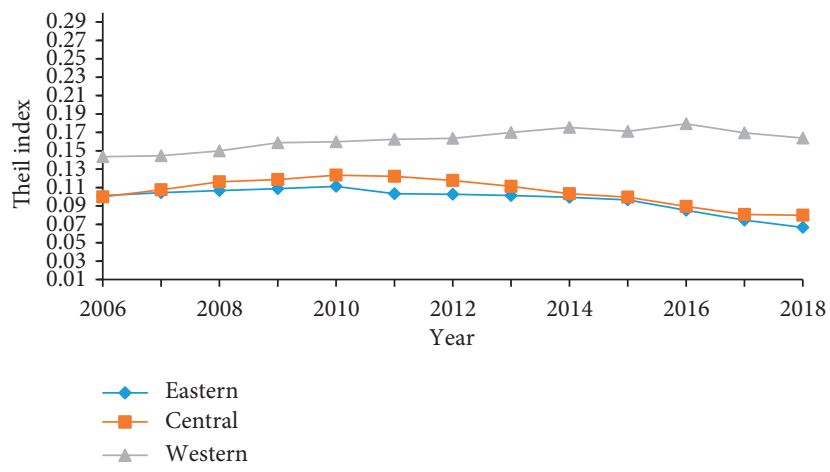

Figure 2: Trend of the Theil coefficient of ecological welfare performance levels in three region of China.

Table 8: Theil coefficient and contribution rate of intragroup and intergroup differences in China.

\begin{tabular}{cccccc}
\hline Year & $\begin{array}{c}\text { Theil } \\
\text { coefficient } T\end{array}$ & $\begin{array}{c}\text { Intragroup } \\
\text { differences } T_{w}\end{array}$ & $\begin{array}{c}\text { Intergroup } \\
\text { differences } T_{b}\end{array}$ & $\begin{array}{c}\text { Intragroup differences } \\
\text { contribution rate }(\%)\end{array}$ & $\begin{array}{c}\text { Intergroup differences } \\
\text { contribution rate }(\%)\end{array}$ \\
\hline 2006 & 0.1148 & 0.0572 & 0.0576 & 0.4983 & 0.5017 \\
2007 & 0.1189 & 0.0566 & 0.0623 & 0.4760 & 0.5240 \\
2008 & 0.1242 & 0.0553 & 0.0689 & 0.4454 & 0.5546 \\
2009 & 0.1287 & 0.0541 & 0.0746 & 0.4204 & 0.5796 \\
2010 & 0.1315 & 0.0531 & 0.0784 & 0.4039 & 0.5961 \\
2011 & 0.1293 & 0.0499 & 0.0794 & 0.3860 & 0.6140 \\
2012 & 0.1279 & 0.0485 & 0.0794 & 0.3792 & 0.6208 \\
2013 & 0.1274 & 0.0476 & 0.0798 & 0.3735 & 0.6265 \\
2014 & 0.1260 & 0.0471 & 0.0789 & 0.3668 & 0.6261 \\
2015 & 0.1224 & 0.0449 & 0.0775 & 0.3713 & 0.6332 \\
2016 & 0.1180 & 0.0438 & 0.0742 & 0.3966 & 0.6034 \\
2017 & 0.1082 & 0.0429 & 0.0653 & 0.4041 & 0.5959 \\
2018 & 0.1034 & 0.0418 & 0.0616 & & \\
\hline
\end{tabular}

differences between the three major regional groups have maintained a continuous decline trend. It can be seen that the differences between intragroup and intergroup differences in various regions of China have decreased. In addition, from the perspective of the contribution rate, during this period, the difference in the contribution rate of the ecological welfare performance group occupies a clear advantage. In general, the regional differences in ecological welfare performance in China continue to decline, and the total contribution rate of the ecological welfare performance 


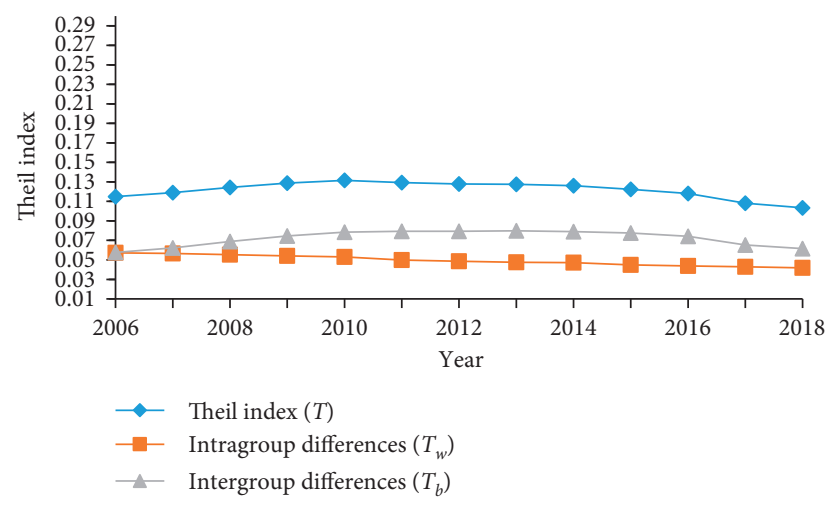

FIGURE 3: Theil trends of intragroup differences' and intergroup differences' Theil coefficient in China.

differences between the three regions is higher than the regional differences.

\section{Conclusions and Suggestions}

5.1. Conclusions. This paper selects China's ecological environment-related data from 2006 to 2018 as the basis and uses the super-efficiency DEA and Malmquist index methods to analyze the evaluation of China's ecological welfare performance from a high-quality development perspective from a static and dynamic perspective.

(1) The average level of ecological welfare performance in 30 major regions of China is 0.800 , which is relatively low, indicating that there is still much room for improvement. Based on the analysis of regional rankings, the top five are Hunan, Shanghai, Beijing, Guangdong, Hubei, and Jiangxi provinces, and the levels are different in different regions; from the regional level, the country as a whole is in the high east, low west, and middle general, In the situation, there is not much difference between the eastern and central regions, and the ecological welfare performance in the western region is low, which indicates that the ecological welfare performance in these regions is closely related to their level of economic development. The level of economic development determines the composition of their industrial structure. Underdeveloped regions often have more traditional extensive growth models, with a high proportion of industries with high pollution, high emissions, and high energy consumption. At the same time, the government has relaxed its tolerance for the environment for economic growth, resulting in lower ecological welfare performance in these regions reality.

(2) Based on the analysis of the results of the dynamic analysis, the overall level of regional ecological welfare performance has improved in recent years and the average Malmquist index has exceeded 1, indicating that the growth pattern of ecological welfare performance has shifted to high quality. As can be seen from the Malmquist index, technological progress has an important role in promoting regional ecological welfare performance in China. Most regions have made significant technological progress, but the degree of progress varies from region to region, indicating that there is room for improvement in resource and environmental efficiency. In the future, we need to continue to improve resource utilization and total control. Some areas have a lot of room for improvement in resource allocation.

(3) Comparison of regional differences: looking at China as a whole, except for 2010, the Theil coefficient of China's regional ecological welfare performance has maintained a downward trend, from the initial 0.1148 to 0.1034 . It can be seen that from a national perspective, regional differences in overall ecological welfare performance have generally maintained a steady downward trend.

In terms of different regions, the Theil coefficient in the western region has maintained a high level among the various regions. During the period of 2006-2018, the difference in ecological welfare performance in the western region was significant; the Theil coefficient in the eastern region and the central region average values are 0.097 and 0.105 , respectively. It can be clearly seen that the eastern region has the smallest difference in ecological welfare performance across the country, and the internal ecological welfare performance levels in various regions are relatively stable.

From the perspective of intragroup and intergroup differences, the intragroup differences and intergroup differences in the three major regions all maintained a continuous downward trend. It can be seen that the intragroup and intergroup differences in various regions of China have decreased. In addition, from the perspective of the contribution rate, during this period, the contribution rate of the difference between the ecological welfare performance groups occupied a clear advantage.

\subsection{Suggestions}

(1) Never touch the ecological red line. When planning the social and economic development goals of each period in the region, the ecological environment is used as a hard constraint, and the utilization of resources is improved in an innovative and technological way to create a compact area and give full play to it. The role of each piece of land in the region, eliminate waste, achieve the control of resources and environmental capacity in terms of total amount, and obtain more benefits through ecological input, that is, improve the level of ecological welfare performance, so as to realize the society sustainable development in all aspects without affecting ecological carrying capacity [21-24]. Encourage regional cooperation with each other to jointly build China's ecological civilization. Of course, the realization of this goal is not a one-off event. China's regional ecological welfare performance is obviously 
different, and the performance value of ecological welfare is low. The region is generally concentrated in the western region, and the prospects are promising. Therefore, it is necessary to encourage the regions in this region to develop synergistically. It is necessary to give full play to their respective advantages in medical technology, energy utilization, education, and economic fields. Mechanisms are needed to effectively improve the level of regional ecological welfare performance, in order to achieve the overall level of ecological welfare in China.

(2) By analyzing the human development index and the ecological consumption index in the ecological welfare performance indicators, it can be known that the provinces with ideal human development levels are concentrated in areas with high ecological consumption, and the ecological carrying capacity of these areas is not as good as before; in other words, these provinces are all at the expense of the ecological environment to obtain economic progress, and the natural ecological balance is not as good as other provinces. Therefore, in the future, we should focus on controlling the total consumption of energy and water resources and be reasonable in the process of improving the economic level. Scientifically, use land resources to avoid causing too much burden on the ecological environment. At the same time, we should change the concept of sacrificing the environment for development in the past, control the total amount of pollutants, save resources, reform the industries with high energy consumption and high pollution, and reopen a new one. The road to economic development must also adhere to the green economy route, reduce fossil energy consumption, and develop the habit of using clean energy, so as to achieve the harmonious development of human and nature [25-27].

(3) The local government assessment index system must include two major indicators: ecological civilization construction and environmental protection. However, environmental protection, ecological construction, and high-quality economic development are not goals that can be achieved in a day or two. Sometimes, in order to achieve this goal, it creates an illusion that the local development is lagging behind. Therefore, individual local governments will not actively interfere with the exhaustive and predatory development models of enterprises, which will lead to the destruction of local ecology, environment, and resources. This is why China, at present, has probably more than 100 laws and regulations concerning environmental protection, but the environmental quality is still deteriorating. This is caused by the inaction of government management. To solve this problem, we should build a supporting environmental protection and ecological construction indicator system. It is necessary to clarify the objectives and contents to be achieved at each stage so as to improve the environmental quality. At the same time, it is necessary to regularly assess the performance of local leaders and competent authorities in ecological construction. For areas with poor ecological governance, it is necessary to ask local leaders and competent authorities. Responsibility is linked to promotion and treatment, and for the ecology in areas with good governance effects, it is necessary to reward local leaders and competent authorities from both material and spiritual aspects. Only by forming links between the results of ecological construction and the interests of officials can they motivate their governance.

(4) Reform the supply side, adjust the production capacity structure, control energy consumption, manage all aspects of the design reform supply side, and coordinate the relationship between man and nature. In addition to keeping up with changes in diversity demand, it is necessary to eliminate production capacity in time. In industries with excessive energy consumption, China's overcapacity is largely caused by the implementation of extensive development models. These excess capacities have caused great damage to the natural environment, coupled with the increase in emissions from the "three wastes." It has intensified the weakening of the environmental carrying capacity. After reforming the supply side and adjusting the production capacity structure, although the problem of overcapacity has not been fundamentally solved, the utilization level of China's industry and major industries has improved. To further improve the ecological environment, it is necessary to eliminate the "zombie enterprises" with little remaining development space and debts as soon as possible and to rectify those industries with high governance costs, high investment, and low output [28-30]. At this stage, China's economic development has slowed down markedly, the international environment has changed significantly, and many enterprises have experienced a significant decline in their operating levels. The state has also introduced many policies to support enterprises, covering market access, credit support, financial support, tax reduction, etc. On the contrary, but even so, we must adhere to the original intention of governance and environmental protection and we must not sacrifice the environment because of economic development.

\section{Data Availability}

All data, models, and code generated or used during the study are included within the submitted article.

\section{Conflicts of Interest}

The authors declare no conflicts of interest.

\section{Acknowledgments}

This work was supported by the School-level Scientific Research Fund Project of Nanjing Institute of Technology, 
“Research on China's Ecological Welfare Performance Evaluation and Improvement PATH from the Perspective of High Quality Development” (Project no. CKJA201905).

\section{References}

[1] H. E. Daly, Beyond Growth: The Economics of Sustainable Development, Beacon Press, Boston, MA, USA, 1996.

[2] D. J. Zhu and S. Zhang, "Research on ecological welfare performance and deepening sustainable development," Journal of Tongji University: Social Science Edition, vol. 5, pp. 106-115, 2014.

[3] H. E. Daly, "Economics in a full world," Scientific American, vol. 293, no. 3, pp. 100-107, 2005.

[4] M. Common, "Measuring national economic performance without using prices," Ecological Economics, vol. 64, no. 1, pp. 92-102, 2007.

[5] T. Dietz, E. A. Rosa, and R. York, "Environmentally efficient well-being: is there a Kuznets curve?" Applied Geography, vol. 32, no. 1, pp. 21-28, 2012.

[6] Z. W. Liu, "Strengthening the real economy to promote high quality development," Industrial Economic Review, vol. 2, pp. 5-9, 2018.

[7] J. Fan, Supply Side Reform Should Focus on Promoting High Quality Development, China Securities Newspaper, China, 2017.

[8] L. J. Long, X. Wang, and B. Guo, "Research on urban ecological welfare performance evaluation based on improved DEA model-taking 35 large and medium cities in China as an example," Journal Os Natural Resources, vol. 4, pp. 595605, 2017.

[9] J. F. Feng and J. H. Yuan, "China's regional ecological welfare performance and its influencing factors," China Science and Technology Forum, vol. 3, pp. 100-105, 2016.

[10] M. L. Song and P. Z. Jin, "Local protection, resource mismatch and environmental welfare performance," Economic Research, vol. 12, pp. 49-63, 2016.

[11] L. M. Xiao and X. P. Zhang, "Temporal and spatial characteristics of the coupling and coordination of green innovation efficiency and ecological welfare performance under the concept of strong sustainability," Journal of Natural Resources, vol. 2, pp. 94-106, 2019.

[12] G. P. Liu, "Research on China's energy welfare performance and its factor decomposition: based on G20 data," Economic Issues Exploration, vol. 1, pp. 28-34, 2017.

[13] L. J. Long, "Research on performance evaluation of ecological welfare in major cities of China-an empirical analysis based on PCA-DEA method and malmquist index," Exploration of Economic Problems, vol. 2, pp. 73-83, 2019.

[14] R. Fare, S. Grosskopfand, and C. Pasurka, "The effect of environmental regulations on the efficiency of electric utilities: 1969 versus 1975," Applied Economics, vol. 21, no. 2, pp. 225-235, 1989.

[15] S. Z. Fang and Q. Xiao, "Research on the performance level and spatial effect of regional ecological welfare in China. China population," Resources and Environment, vol. 3, pp. 3-12, 2019.

[16] M. D. Zang, D. J. Zhu, and G. P. Liu, "Ecological welfare performance: concept, connotation and G20 evidence," China Population-Resources and Environment, vol. 5, pp. 118-124, 2013.

[17] B. N. Guo and Y. Bu, "Performance evaluation and influencing factors of urban ecological welfare in the Yangtze River economic belt-taking 110 cities in the Yangtze River economic belt as an example," Enterprise Economy, vol. 8, pp. 30-37, 2018.

[18] H. B. Du, L. J. Huang, and C. Zhang, "Regional differential decomposition and convergence of provincial ecological welfare performance in China," Ecological Economy, vol. 3, pp. 187-193, 2019.

[19] H. Zhang, W. Yu, and C. Y. Sun, "Research on the relationship between ecological welfare performance and economic sustainable development in Liaoning Province," Journal of Resources and Ecology: English, vol. 1, pp. 39-47, 2019.

[20] R. Yang and R. Zhang, "Research on green development evaluation from the perspective of ecological welfare performance-taking qingdao city as an example," Ecological Economy, vol. 12, pp. 58-63, 2018.

[21] Y. Y. Zhang, Q. C. Dong, and M. Ni, "Analysis of the development of service industry and "structural deceleration"-on the construction of modern economic system with high quality development," Economic Development, vol. 2, pp. 23-35, 2018.

[22] K. R. Shen, "Taking the supply-side structural reform as the main line to improve the quality of economic development," Political Economy Review, vol. 1, pp. 51-55, 2018.

[23] P. Andersen and N. C. Petersen, "A procedure for ranking efficient units in data envelopment analysis," Management Science, vol. 39, no. 10, pp. 1261-1264, 1993.

[24] W. Liu and Q. Zhao, "The construction of ecological welfare rights and its relief system," Guangxi Social Sciences, vol. 11, pp. 84-90, 2017.

[25] X. N. Qiao and D. Wang, "Ecological compensation for flow pollution: implementation subject, condition and economic performance," Environmental Economic Research, vol. 4, pp. 123-140, 2017.

[26] Y. D. Xu, P. Yan, and L. F. Tong, "Research on the spatial and temporal differentiation pattern of ecological welfare performance level in China's provincial regions," Regional Economic Review, vol. 4, pp. 123-131, 2017.

[27] E. A. M. Bokkers and I. J. M. de Boer, "Economic, ecological, and social performance of conventional and organic broiler production in The Netherlands," British Poultry Science, vol. 50, no. 5, pp. 546-557, 2009.

[28] Y. Tsur and A. Zemel, "Welfare measurement under threats of environmental catastrophes," Journal of Environmental Economics and Management, vol. 52, no. 1, pp. 421-429, 2006.

[29] M. Meul, S. Passel, and D. Fremaut, "Higher sustainability performance of intensive grazing versus zero-grazing dairy systems," Agronomy for Sustainable Development, vol. 32, no. 3, pp. 629-638, 2012.

[30] D. Posads-Sánchez and P. R. Killeen, "Does satiation close the open economy?" Learning \& Behavior, vol. 33, no. 4, pp. 387-398, 2005. 